\title{
Assessing the Impact of the Change in the Tire Pressure on the Rolling Resistance and Fuel Consumption
}

\author{
František Synák ${ }^{1 *}$, Alica Kalašová ${ }^{1}$ \\ 1 University of Žilina, Faculty of Operation and Economics of Transport and Communications Department od \\ Road and Urban Transport, Univerzitná 1, 01023 Žilina, Slovak Republic \\ * Corresponding author's e-mail: frantisek.synak@fpedas.uniza.sk
}

\begin{abstract}
The value of tire pressure affects a number of important vehicle features. The article pays attention to assessing the impact of the change in the tire pressure on both the rolling resistance and fuel consumption. The measurements were performed with four different values of tire pressure. The impact of the change in the tire pressure on the rolling resistance was measured during the driving tests. In order to measure the rolling resistance during tests, the measurement methodology was devised and a device for measuring the rolling resistance was constructed. The measurement of the impact the tire pressure change on the fuel consumption was performed via vehicle dynamometer. The result showed a linear dependence between the tire pressure and rolling resistance. These results measured points to the importance of keeping the correct value of the tire pressure in relation to the fuel consumption.
\end{abstract}

Keywords: tire pressure, fuel consumption, rolling resistance.

\section{INTRODUCTION}

The value of tire pressure affects its stiffness $[1,2]$, lifespan as well as the vehicle stopping distance $[3,4,5]$, its directional stability and performance while running $[6,7,8$, ] additionally, it influences the noisiness of driving $[9,10]$, the value of rolling resistance together with the value of fuel consumption $[11,12]$ and many other aspects that affect the level of driving safety and economy $[13,14,15]$. Such value of tire pressure is not stable, since it varies throughout its lifetime according to various factors. These include the tire inflation after being mounted on a rim, gradual tire pressure reduction resulting from leakages, and so on. The manufacturer defines a correct tire pressure; however, the owners, drivers or mechanics are responsible for its maintenance. Since 1.11.2012, all the new vehicle models in the European Union, and since 1.11.2014, all the vehicles constructed in the European Union, including the models produced before 1.11.2012, have to be equipped with a tire pressure monitoring system, known as TPMS [16]. However, the information indicating that one of the tires does not have the pressure prescribed by the manufacturer does not mean that the drivers are to remedy it. The TPMS function is also connected with some problems such as battery life in the sensors located on the wheel valves or the necessity of calibration after each wheel replacement if the TPMS system is gaining the data from the ABS [17]. In practice, drivers do not carry out these duties and are driving with the low tire pressure indicator constantly alight. According to [18] 68\% of vehicles is driven with low tire pressure, while $21 \%$ comprises the vehicles with a tire pressure of $180 \mathrm{kPa}$ up to $160 \mathrm{kPa}$, and $27 \%$ with pressure of $160 \mathrm{kPa}$ up to $110 \mathrm{kPa}$. Similar research can be also seen in [19] according to which up to $80 \%$ of vehicles do not have the prescribed tire pressure while driving. The tire pressure value affects the size of tire deflection during its rolling. Thus, part of the energy delivered to the engines and taken from the fuel is consumed for a tire to be rolled. The lower tire pressure, the higher tire deflection and the higher energy from the fuel needed for tires to be rolled [20]. 
Table 1. Tire energy efficiency class depending on the RRC value [22]

\begin{tabular}{|c|c|}
\hline RRC in $\mathrm{kg} / \mathrm{t}$ & Energy efficiency class \\
\hline $\mathrm{RRC} \leq 6.5$ & $\mathrm{~A}$ \\
\hline $6,6 \leq \mathrm{RRC} \leq 7.7$ & $\mathrm{~B}$ \\
\hline $7,8 \leq \mathrm{RRC} \leq 9.0$ & $\mathrm{C}$ \\
\hline Empty & $\mathrm{D}$ \\
\hline $9.1 \leq \mathrm{RRC} \leq 10.5$ & $\mathrm{E}$ \\
\hline $10.6 \leq \mathrm{RRC} \leq 12.0$ & $\mathrm{~F}$ \\
\hline $\mathrm{RRC} \geq 12.1$ & $\mathrm{G}$ \\
\hline
\end{tabular}

However, the deflection rate and the value of rolling resistance, although significant. are not only affected by the pressure in the tire alone. There are many other factors such as tire construction, materials used and so on that have certain influence on the tire deflection rate, as well as on the value of rolling resistance [21]. According to [22], the tire manufacturers are obliged to label the tires according to their energy efficiency class. Table 1 shows the division of tires for passenger vehicles into particular energy efficiency classes, according to the value of rolling resistance coefficient (RRC).

The values from Table 1 relate to the tire inflated to the prescribed pressure. At a certain load, a tire causes some rolling resistance. The purpose of the measurements was to find out the difference in the value of the tire rolling resistance in case that a tire pressure has changed. When the rolling resistance coefficient is changed, and thus - the value of rolling resistance - it is assumed that the fuel consumption will change as well. Hence, the difference in the tire pressure can also lead to a theoretical difference in the tire energy efficiency.

The measurements in this article were divided into two parts.

The first part comprises measuring of the change in rolling resistance based on the change in the tire pressure. The measurements were performed by a driving test with different

Table 2. The weight of particular wheels of vehicle during measurements

\begin{tabular}{|c|c|c|}
\hline Wheel & Wheel weight [kg] & Axle weight [kg] \\
\hline Left front & 400 & \multirow{2}{*}{780} \\
\cline { 1 - 2 } Right front & 380 & \\
\hline Left rear & 500 & \multirow{2}{*}{920} \\
\hline Right rear & 420 & \\
\hline
\end{tabular}

tire pressures via measuring the force needed for a vehicle to be towed.

The second part comprises measuring of the change in fuel consumption depending on the value of rolling resistance measured in the first part. The measurement results demonstrate the impact rate of the change in tire pressure on the rolling resistance as well as fuel consumption.

\section{MEASUREMENT METHODOLOGY}

The main goal of the measurements was to quantify the rate of change in the rolling resistance and the impact of change in the rolling resistance on fuel consumption depending on the tire pressure. The vehicle used for measurements was Škoda Fabia 1.9 TDi, 66 kW, engine code AGR. The vehicle tires were Continental Winter Contact TS 860 with size of 195/65 R15 $91 \mathrm{~T}$. The energy efficiency class of tires is " $\mathrm{C}$ " and the depth of the tread was approximately of $6 \mathrm{~mm}$ during measurements. The prescribed tire pressure was given in the value of $230 \mathrm{kPa}$. The values of rolling resistance and fuel consumption were determined at the tire pressures of $150 \mathrm{kPa}$, $190 \mathrm{kPa}, 230 \mathrm{kPa}$ and $260 \mathrm{kPa}$.

The load on particular wheels and axles during measurements is given in the Table 2. The loads were gained by means of Portable weighing system PW-10 with weighing accuracy of \pm $10 \mathrm{~kg}$ per wheel [22].

As seen from the Table 2, the vehicle weight was $1700 \mathrm{~kg}$ during measurements.

The measurements can be divided into two parts. The first part is the measurement of the rolling resistance based on the tire pressure and the second part is the measurement of the change in the fuel consumption caused by the change in the rolling resistance.

The quantification of change in the rolling resistance was performed via driving tests. The principle of measuring was to measure the force needed for the vehicle to be towed with specific tire pressures. The positions while measuring the change in the rolling resistance caused by the change in the tire pressure are displayed in the Figure 1.

The position 1 symbolizes the vehicle towed, and the position 4 symbolizes the flange attached to the bumper beam. The dynamometer is under the number 6 , and it was screwed to the towing bar which can be seen under the number 7 . The towing bar was through the coupling device seen 


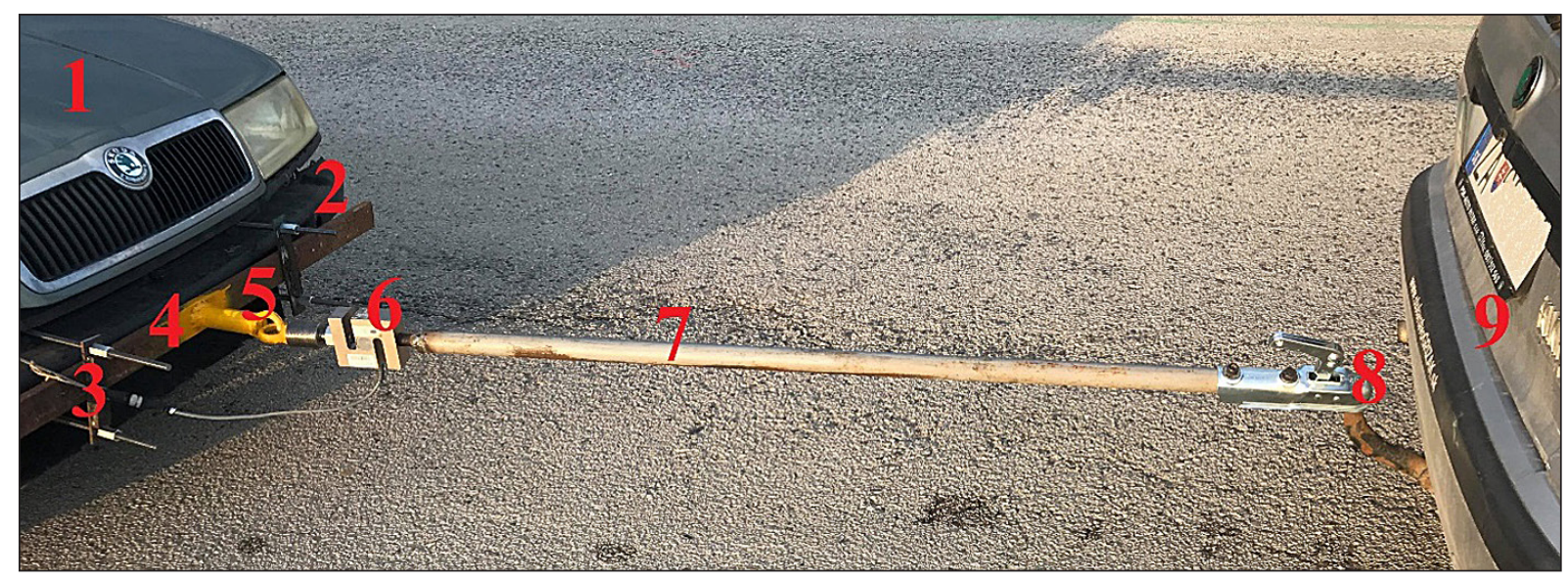

Fig. 1. Measurement of the change in the rolling resistance value as a function of tire pressure change

under the number 8 attached to the tow vehicle marked by the number 9 .

Such composition for the vehicle to be towed and tractive force to be measured had to enable the mutual vehicle asymmetry both horizontally and vertically while manipulating with vehicles. At the same time, the coupling device had to be located to the vehicle axis of gravity as far as possible in order to avoid the occurrence of parasite forces. In order to meet these requirements, joining the couple device with tow vehicle was done via bracket attached to the bumper beam and joint. Figure 2 displays in detail how is the coupling device attached to the tow vehicle.

As seen from the Figure 2, the position 1 symbolizes the tow vehicle to which is via bracket 3 that is screwed to the bumper beam 2 attached the towing bar seen under the number 7. Joint 5 enables mutual horizontal and vertical asymmetry of the vehicle. The device under the number 6 is a dynamometer reading the force in the device used for the vehicle to be towed.

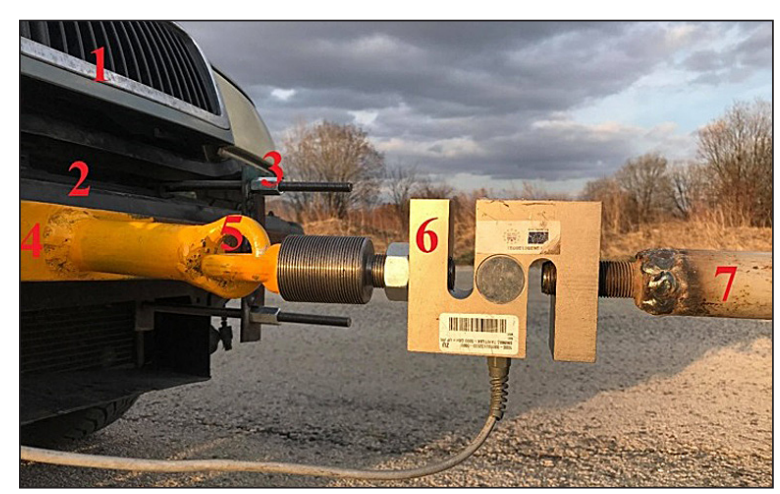

Fig. 2. Detail of coupling device
During the measurement, the vehicle with a certain pressure in all 4 tires was towed by the towing vehicle with a constant speed on the trajectory of $400 \mathrm{~m}$ long. While towing, a force needed for the vehicle to be towed was recorded via dynamometer (Figure 2, position 5) and further, through the IPRE software communicating with the dynamometer, it was recorded at the frequency of 20 times per second. In order to avoid the impacts, the vehicle was towed uphill with a gradient of about $2 \%$. This led to the fact that the towing vehicle had to make its tractive force constantly as well as the vehicle towed did not tend to get closer to the tow vehicle as a result of its inertia. Thus, it avoided the impacts in a tractive system. The driving tests through towing have always been performed under the same conditions with the same weight of vehicle towed. Thus, the value of other driving resistances was constant during all the driving tests, and the only driving resistance that varied was the rolling resistance due to change in the tire pressure.

The driving tests per particular tire pressures were repeated 5 times and the average value was calculated subsequently.

The change in fuel consumption caused by the change in the tire pressure and in the rolling resistance was measured on the MAHA MSR 1050 vehicle dynamometer. The main advantage of it is that other factors influencing the fuel consumption during the measurements through driving test, such as wind, road unevenness and so on are avoided. The MAHA MSR 1050 vehicle dynamometer enables a simulation of driving resistances via braking, or moving of dynamometer cylinders by a certain force. The measurements were performed at the driving speeds of $50 \mathrm{~km} \cdot \mathrm{h}^{-1}$ 
and $80 \mathrm{~km} \cdot \mathrm{h}^{-1}$ on $5 \mathrm{~km}$ long trajectory for each measuring. While driving at the speed of 50 $\mathrm{km} \cdot \mathrm{h}^{-1}$, the third and fourth transmission gears were used, and at the speed of $80 \mathrm{~km} \cdot \mathrm{h}^{-1}$, the fourth and fifth transmission gears used. Before measuring, it was necessary to insert the values of particular driving resistances into the dynamometer computer. The rolling resistance was calculated according to the relation:

$$
O_{r}=m \cdot g \cdot C R R
$$

Where: $O_{r}-$ rolling resistance $[\mathrm{N}], m-$ vehicle mass $[\mathrm{kg}], g-$ gravitational acceleration, $\left[\mathrm{m} \cdot \mathrm{s}^{-2}\right]$, CRR - rolling resistance coefficient [-] [24].

The relation used to calculate the air resistance was as follows:

$$
O_{a}=0.5 \cdot \rho \cdot c_{X} \cdot S \cdot v^{2}
$$

Where: $O_{a}-$ air resistance $[\mathrm{N}], \rho-$ the specific air mass. $1.29 \mathrm{~kg} / \mathrm{m}^{3}$ at $0{ }^{\circ} \mathrm{C}$ and pressure of $0.101325 \mathrm{MPa}, c_{X}-$ the body shape coefficient [-], $S$ - the size of vehicle front face $\left[\mathrm{m}^{2}\right], v-$ the vehicle driving speed $[\mathrm{m} / \mathrm{s}][25]$.

The sum of driving resistances for the driving speed of $50 \mathrm{~km} \cdot \mathrm{h}^{-1}$ was rounded to $200 \mathrm{~N}$. At the same time, the effect of the change in the tire pressure was studied at the driving resistances of $100 \mathrm{~N}$.

The sum of driving resistances with the driving speed of $80 \mathrm{~km} \cdot \mathrm{h}^{-1}$ was $323 \mathrm{~N}$. The value of the change in the rolling resistance caused by the change in the tire pressure at their lowest and highest points was added to the driving resistances.

The fuel consumption was determined through the VAG V.C.D.S 11.11.1. diagnostic software which is communicating with the engine control unit. The consumption is given in $\left[1 \cdot h^{-1}\right]$, and therefore it needs to be converted into $[1 \cdot 100$ $\left.\mathrm{km}^{-1}\right]$ as usual. The first step was to calculate the fuel consumption per one second:

$$
Q_{s}=Q_{h} / 3600
$$

Where: $Q_{s}-$ the fuel consumption $\left[1 \cdot \mathrm{s}^{-1}\right], Q_{h}-$ the fuel consumed $\left[1 \cdot h^{-1}\right]$

Further, it was necessary to calculate the fuel consumed for the whole time of measurements:

$$
Q_{c}=Q_{s} \cdot t
$$

Where: $Q_{c}$ - the fuel consumed [1], $t$ - time of measuring [s]

The last step comprised the calculation of fuel consumption in $\left[1 \cdot 100 \mathrm{~km}^{-1}\right]$ according to the formula:

$$
Q_{100}=Q_{c} / s \cdot 100000
$$

Where: $Q_{100}$ - the fuel consumption $\left[1 \cdot 100 \mathrm{~km}^{-1}\right]$, $Q_{c}$ - the fuel consumed [1], $s$ - the trajectory of measurements [m]

\section{RESULTS}

The differences in the rolling resistance caused by the change in tire pressures are given in Table 3 .

The rolling resistance in the tires inflated to the pressure of $230 \mathrm{kPa}$ that is prescribed by the manufacturer is considered as basic, and therefore signed as " 0 ".

The difference between the rolling resistance in the tire with pressure of $260 \mathrm{kPa}$ and of 150 $\mathrm{kPa}$ amounted to $49.6 \mathrm{~N}$.

The impact of such change in the rolling resistance on the fuel consumption can be seen in Table 4.

Table 4 shows how the change in the tire pressure as well as the rolling resistance, affected the fuel consumption. The change in fuel consumption was not the same at each stage of measurement, since it varied from $+4.3 \%$ up to $+10.2 \%$. While driving at the speed of $50 \mathrm{~km} \cdot \mathrm{h}^{-1}$, the difference in the fuel consumption measured was higher than while driving at the speed of $80 \mathrm{~km} \cdot \mathrm{h}^{-1}$. Such uneven change in the fuel consumption can be the result of the changes in specific fuel consumption and the share of the rolling resistance change on the overall driving resistance [26].

Changing into another transmission gear, together with the change in the value of the driving resistances, affected the engine load, which in turn influenced the value of specific fuel consumption. However, there was an increase in the fuel consumption due to the increase in the rolling resistance at each of the measurement.

While measuring, the tires used were of " $\mathrm{C}$ " energy efficiency class. It means that the value of rolling resistance coefficient " $\mathrm{f}$ " varies from 0.0078 up to 0.0090 , as also seen in the Table 1 . With interval $\mathrm{f}=0.0084$ and the vehicle mass substituted into the relation 4 , and when avoiding mechanical resistances, it can be assumed that the value of rolling resistance would be of $140 \mathrm{~N}$. The

Table 3. Difference in the rolling resistance due to different tire pressure

\begin{tabular}{|c|c|c|c|c|}
\hline Tire pressure $[\mathrm{kPa}]$ & 150 & 190 & 230 & 260 \\
\hline $\begin{array}{c}\text { Difference in rolling } \\
\text { resistance }[\mathrm{N}]\end{array}$ & +17.8 & +6.7 & 0 & -31.8 \\
\hline
\end{tabular}


Table 4. The impact of the change in the rolling resistance on the fuel consumption

\begin{tabular}{|c|c|c|c|c|c|}
\hline $\begin{array}{c}\text { Number of } \\
\text { measurement }\end{array}$ & $\begin{array}{c}\text { Driving speed } \\
{\left[\mathrm{km} \cdot \mathrm{h}^{-1}\right]}\end{array}$ & $\begin{array}{c}\text { Transmission } \\
\text { gear }\end{array}$ & $\begin{array}{c}\text { Driving } \\
\text { resistances [N] }\end{array}$ & $\begin{array}{c}\text { Fuel consumption } \\
{\left[\mathrm{l} \cdot 100 \mathrm{~km}^{-1}\right]}\end{array}$ & $\begin{array}{c}\text { Difference } \\
{[\%]}\end{array}$ \\
\hline \multirow{2}{*}{1} & \multirow{2}{*}{50} & \multirow{2}{*}{3} & 100 & 4.06 & \multirow{2}{*}{+9.6} \\
\hline & & & 149.6 & 4.45 & \\
\hline \multirow{2}{*}{2} & \multirow{2}{*}{50} & \multirow{2}{*}{4} & 100 & 2.75 & \multirow{2}{*}{+10.2} \\
\hline & & & 149.6 & 3.03 & \\
\hline \multirow{2}{*}{3} & \multirow{2}{*}{50} & \multirow{2}{*}{3} & 200 & 4.57 & \multirow{2}{*}{+7.2} \\
\hline & & & 249.6 & 4.90 & \\
\hline \multirow{2}{*}{4} & \multirow{2}{*}{50} & \multirow{2}{*}{4} & 200 & 3.31 & \multirow{2}{*}{+9.4} \\
\hline & & & 249.6 & 3.62 & \\
\hline \multirow{2}{*}{5} & \multirow{2}{*}{80} & \multirow{2}{*}{4} & 323 & 4.88 & \multirow{2}{*}{+4.3} \\
\hline & & & 372.6 & 5.09 & \\
\hline \multirow{2}{*}{6} & \multirow{2}{*}{80} & \multirow{2}{*}{5} & 323 & 4.08 & \multirow{2}{*}{+5.9} \\
\hline & & & 372.6 & 4.32 & \\
\hline
\end{tabular}

mechanical resistances can be avoided due to the neutral gear used in the vehicle towed since these resistances were of very low values. By deflating the tires down to the pressure of $150 \mathrm{kPa}$, the rolling resistance increased from $17.8 \mathrm{~N}$ to $157.8 \mathrm{~N}$. When substituting again, it is possible to notice that the rolling resistance coefficient has reached the value of 0.0094 corresponding to the tire's energy efficiency class "E". By inflating the tires up to the pressure of $260 \mathrm{kPa}$, the rolling resistance decreased by $31.8 \mathrm{~N}$, in comparison with the rolling resistance at the tire pressure of 230 $\mathrm{kPa}$. Here, the tire rolling resistance is $\mathrm{f}=0.0064$ meaning it is of " $\mathrm{A}$ " energy efficiency class.

\section{CONCLUSION}

The article pointed out to the importance of having the correct tire pressure from the point of view of rolling resistance and fuel consumption. As seen from the measurements, a decrease in the tire pressure leads to an increase in the rolling resistance. The vehicle engine must perform some work in order to overcome the rolling resistance. Therefore, it is necessary to deliver a certain amount of energy from fuel to the engine, and thus, while increasing the rolling resistances, it the fuel consumption needs to be increased as well.

Such increase is also connected with higher emission production. Every litre of diesel fuel consumed leads to the production of at least 2.7 $\mathrm{kg}$ of $\mathrm{CO}_{2}$ which is known as a major contributor to the global warming [27]. Driving with the tire pressure that is lower than its prescribed value given by the manufacturer, thus, results in an unnecessary production of $\mathrm{CO}_{2}$. It is important to keep the right value of tire pressure not only for the economic reasons but for the ecological issues concerning the emission production. Besides, driving with low tire pressure also leads to an unnecessary use of non-renewable fuels.

On the basis of the results from Table 3, it is possible to recommend driving with higher tire pressure than prescribed by the manufacturer, since there has been a decrease in the rolling resistance as well as fuel consumption (Table 4). However, the tire pressure does not only affect the rolling resistance, it also has impact on many other important aspects such as tire traction and lifespan, stopping distance, surface stability and so on [28]. Thus, intentionally increasing the tire pressure over the level recommended by the manufacturer, as well as its decreasing, would not be appropriate.

Changing the tire pressure led to such a change in the value of rolling resistance coefficient that the tire did not correspond to the values of the energy efficiency class according to which it had been classified [16]. During the measurements, decreasing the tire pressure caused such an increase in the rolling resistance that the tire of energy efficiency class " $C$ " corresponded to the class "E". On the other hand, increasing the tire pressure would improve the tire energy efficiency to the level of " $A$ ". On the basis of these theoretical findings, it may be said that when purchasing the tires with energy efficiency class " $A$ " that usually requires a higher purchase price, and driving with low tire pressure, it is possible to come into the state when the tire would be classified into the 
energy efficiency class " $C$ ". Besides these, the effect of increasing the fuel consumption while driving with low tire pressure can be ranked as a less dangerous factor.

The measurement results were also affected by the vehicle used for measuring, specifically for the fuel consumption measuring. This compression ignition engine vehicle had relatively large volume of 1.91 . In the case of using a spark ignition engine vehicle with lower volume, a substantial difference in the fuel consumed would be assumed.

The dependence between the tire pressure, rolling resistance and fuel consumption had a linear development. Similar results can be also seen in the publication [29] in which the measurements were performed according to the methodology from the SAE J1269 standard test that enables a simulation of any tire pressure and any tire load.

All of the measurements of rolling resistance from this article were performed while driving at the same speed. In the case of measuring at higher driving speeds, a slightly higher rolling resistance may be assumed. However, an increase in the rolling resistance would be the same at each tire pressure as also seen in the publication [11] in which the results represent the measurements simulated at the driving speeds falling within $70 \mathrm{~km} \cdot \mathrm{h}^{-1}$.

The tire pressure is important from the various points of view and, therefore, it requires appropriate attention and maintenance.

\section{Acknowledgments}

Contribution has been prepared on the basis of the grant VEGA no. 1/0436/18 - Externalities in road transport, an origin, causes and economic impacts of transport measures.

\section{REFERENCES}

1. Wang, HJ., Xu, WB., Li, B., Hao, KM., Jiang, C., Based on 1/4 vehicle suspension system for tire pressure and tire stiffness Nonlinear Studies, Mechanical design and power engineering, PTS 1 and 2, Vol. 490-491, 2014, 383-387, DOI: 10.4028/ www.scientific.net/AMM.490-491.383.

2. Semetko, J., Janosko, I., Increase of driving pulls of the tractor by trailer. Actual tasks on agricurtular engineering, Vol. 31, 2003, 59-64.

3. Reina, G., Gentile, A., Messina, A., Tyre pressure monitoring using a dynamical model-based estimator, Vehicle system dynamics, Vol. 53, 568-586,
DOI: $10.1080 / 00423114.2015 .1008017$.

4. Poliak, M., Hammer, J., Reuter, N., Poliakova, A., The impact of the transport route on the cost of the transfer, 11th International Scientific and Technical Conference on Automotive Safety, 2018, DOI: 10.1109/AUTOSAFE.2018.8373319.

5. Tang, T., Anupam, K., Kasbergen, C., Scarpas, A., Study of influence of operating parameters on braking distance, Transportation research record, 2017, 139-148, DOI: 10.3141/2641-16.

6. Wang, F., Chen, H., Guo, KH., Cao, DP., A novel integrated approach for path following and directional stability control of road vehicles after a tire blow-out, Mechanical systems and signal processing, Vol. 93, 2017, 431-444, DOI: 10.1016/j.ymssp.2017.02.016.

7. Mikulski, J., State of safety in the Polish land transport, Safety of marine transport, 2015, 294-274, DOI: $10.1201 / \mathrm{b} 18515-44$.

8. Skrucany, T., Semanova, S., Kendra, M., Figlus, T., Vrabel, J., Measuring of mechanical resistances of a heavy good vehcle by coastdown test, Advances in science and technology-research journal, Vol. 12, 2018, 214-221, DOI: 10.12913/22998624/91889.

9. Xiong, JQ, Research on influence mechanism of tire pressure on the ride comfort of automobile, 4th International Conference on Environmental Science and Material Application (ESMA), Vol. 252, 2019, DOI: $10.1088 / 1755-1315 / 252 / 2 / 022099$.

10. Mikulski, J., Role of telematics in reducing the negative environmental impact of transport, Transport system telematics, Vol. 104, 2010, DOI: 10.1007/978-3-642-16472-9_2.

11. Suyabodha, A., A relation between tyre pressure and rolling resistance force under different vehicle speed, International Conference on Mechanical, Aeronautical and Automotive Engineering (ICMAA), Vol. 108, 2017, DOI: 10.1051/matecconf/201710812004.

12. Szczucka-Lasota, B., Kaminska, J., Krzewska, I., Influence of tire pressure on fuel consumption in trucks with installed tire pressure monitoring system (TPMS), Scientific journal of Silesian university of technology -series transport, Vol. 103, 2019, 167-181, DOI: 10.20858/sjsutst.2019.103.13.

13. Jurecki, R., Poliak, M., Jaskiewicz, M., Young adult drivers: simulated behaviour in a car - following situation, Promet - Traffic \& transportation, Vol. 29, 2017, 381-390, DOI: 10.7307/ptt.v29i4.2305.

14.Erd, A., Jaskiewicz, M., Koralewski, G., Rutkowski, G., Stoklosa, J., Experimental research of effectiveness of brakes in passenger cars under selected conditions, 11th International Scientific and Technical Conference on Automotive Safety, 2018, DOI: 10.1109/AUTOSAFE.2018.8373299. 
15. Dobrowolski, D., Drozdziel, P., Madlenak, R., Siluch, D., Daily kilomatrega analysis for selected vehicle groups, Vol. 12, 2018, 39-46, DOI: 10.12913/22998624/92109.

16. Regulation No 141 of the Economic Commission for Europe of the United Nations (UN/ECE) Uniform provisions concerning the approval of vehicles with regard to their Tyre Pressure Monitoring Systems (TPMS).

17. Wang, LQ, Zhang, Z., Yao, YN., Han, ZQ., Wang, B., Monitoring method of indirect TPMS under steering situation, 3rd International Conference on Mechanical, Industrial, and Manufacturing Engineering (MIME), 2016, 187-190, DOI: 10.12783/ dtetr/mime2016/10229.

18. The tyre - Rolling resistance and fuel savings, Online: http://www.dimnp.unipi.it/guiggiani-m/Michelin_Tire_Rolling_Resistance.pdf, (11.12.2019).

19. Continettal - tyres - Engineering in Germany, Online: http://www.pneubartos.cz/download/48_conti_vady_pass_cs.pdf, (11.12.2019).

20. Mikulova, Z., Vitazek, I., Proportion of volatile matter in selected biofuels, 23rd International $\mathrm{PhD}$ Students Conference (MendelNet), 2016, 829-897.

21. Akutagawa, K., Technology for reducing tire rolling resistance, Tribology online, Vol. 12, 2017 , 99-102, DOI: $10.2474 /$ trol.12.99.

22. Regulation (EC) No $1222 / 2009$ of the European Parliament and of the Council of 25 November 2009 on the labelling of tyres with respect to fuel efficiency and other essential parameters.
23. User manual for Portable weighing system PW-10.

24. Pexa, M., Mader, D., Cedik, J., et all., Experimental verification of small diameter rollers utilization in construction of roller test stand in evaluation of energy loss due to rolling resistance, Measurement, Vol. 152, 2020, DOI: 10.1016/j.measurement.2019.107287.

25. Skrucany, T., Harantova, V., Kendra, M., Barta, D., Reducing energy consumption by passenger car with using of non-electrical hybrid drive technology, Advances in science technology research journal, Vol. 11, 2017, 166-172, DOI: $10.12913 / 22998624 / 66505$.

26. Osipowocz, T., et all., The analysis of technical condition common rail fuel system components, 11th International Scientific and Technical Conference on Automotive Safety, 2018, DOI: 10.1109/ AUTOSAFE.2018.8373304.

27. Dhawan, P., Kapoor, AU, Capturing exhaust CO2 gas using molten carbonate fuel cells, Advances in science technology - research journal, Vol. 10, 2016, 147-151, DOI: 10.12913/22998624/61946.

28. Ondrus, J., Kolla, E., Practical use of the braking attributes measurement results, 18th International Scientific Conference on LOGI, Vol. 134, 2017, DOI: $10.1051 /$ matecconf/201713400044.

29. Bachman, LJ, Do changes in temperature and inflation pressure affect rolling resistance during road and track testing for fuel economy of class 8 tractor - trailers? Tire science and technology, Vol. 46, 2018, 93-104, DOI: 10.2346/tire.18.460203. 